\title{
El treball cooperatiu de les ciències socials i les matemàtiques. Accions de connexió universitària catalana*
}

\author{
Antoni Gavaldà, Josep M. Pons, Luisa Girondo, \\ Carme Olivé, Víctor Grau, Jordi Suñé \\ Universitat Rovira i Virgili \\ Jacint Torrents, Joan Callarisa, Pilar Arumí \\ Universitat de Vic \\ antoni.gavalda@urv.cat
}

Resum: Aquest article pretén mostrar experiències de treball cooperatiu a dues universitats catalanes - la Universitat Rovira i Virgili (URV) i la Universitat de Vic (UVic) - en dues àrees de didàctica: la de les ciències socials i la de matemàtiques. A partir de treballs especifics de classe, s'ha fet una immersió teòrica i pràctica en el treball cooperatiu als alumnes del grau d'Educació Primària. En la part pràctica s'han analitzat les seqüències procedimentals dels treballs efectuats i s'han detectat actuacions positives $i$ d'altres de millorables per ajudar els futurs mestres a ser competents en el treball cooperatiu amb els alumnes de primària.

Paraules clau: treball cooperatiu, cooperació a l'escola, valors cooperatius, aprenentatge significatiu, currículum d'educació primària

\begin{abstract}
This paper relates some experiences of cooperative work in two Catalan public universities: the Universitat Rovira $i$ Virgili and the Universitat de Vic. The cooperative work was carried out in the disciplines of Social Sciences and Mathematics. We implemented specific exercises in the degree in Primary Education to enable students to engage in and experience cooperative work on both a theoretical and a practical level. During the practical part, we analysed working procedures and found that while some were decidedly positive, there were others which could be improved. The analysis aims to help future teachers to become competent in adopting cooperative methodologies with their own primary school students.
\end{abstract}

Keywords: cooperative work, cooperation in school, cooperative principles, significant learning, primary school curriculum

\footnotetext{
* Aquest treball forma part del projecte "Laprenentatge des de la cooperació, a les didàctiques de les ciències socials i les matemàtiques: lligam entre universitat i escola” (2014 ARMIF 00004), subvencionat per l'Agència de Gestió d’Ajuts Universitaris i de Recerca de la Generalitat de Catalunya.
} 


\section{Cooperació? Vigilem, no és una moda pas- satgera}

Lauge del capitalisme, històricament, ha primat més l'individualisme que no pas l'èxit de l'organització grupal. Aquesta deriva ha influenciat clarament en el tipus d'educació rebuda. Sabem que existeixen mancances educatives que dificulten l'adquisició de competències socials de tot ordre, i que en el fons esdevenen necessàries per fer front a reptes socialment rellevants. La resolució d'aquestes problemàtiques relacionals difícilment s'assoliran treballant només de manera individual, $\mathrm{i}$ creiem que han de ser unes pràctiques vivencials continuades les que afavoriran la col-laboració entre alumnes, per formar en definitiva ciutadans. És en aquest sentit, per tant, que una de les tasques de l'educació serà ajudar a ensenyar l'alumne, des de la pràctica, que la cooperació és una forma de comprensió, de diàleg, de decisió, d'aprenentatge compartit, que permet avançar per poder prendre postures i decisions particulars, personals i col-lectives. A l'alumnat, per tant, si volem que sigui protagonista d'aquest nou temps de relació i d'intercanvi, no li podem escatimar maneres de treballar amb la realitat d'avui: sol, indiscutiblement, pot i podrà fer unes determinades activitats, i en grup podrà fer les mateixes i n'haurà de fer moltes altres. Convençuts d'aquest axioma, caldrà habilitar l'alumne per fer possible que la col-laboració i la cooperació siguin elements normals d'aprenentatge. Conseqüentment, cal apostar per sistemes d'aprenentatge cooperatiu.

Lesperit cooperatiu, ja ho hem insinuat, no es construeix en l'alumne de forma natural i espontània. Almenys no es consolida. Pujolàs (2008: 21) ho determinà de forma molt clara: "l'única manera existent per tal que l'alumne aprengui a cooperar és cooperant". Així doncs, l'alumnat requereix posar en pràctica intervencions didàctiques que permetin desenvolupar valors cooperatius necessàriament presents a l'ensenyament per aconseguir aquesta finalitat. De quins valors, però, estem parlant? Gavaldà (2000:15-17), en aquest sentit, concretà una relació inspirada en el món cooperatiu que havia estudiat $i$ indicà entre altres: el potencial de la valoració d'idees divergents; la necessitat de diàleg i consens per llimar aspreses de plantejament; tenir llibertat d’opinió per articular una expressió personal per poder ser discutida; posseir igualtat de vot en la presa de decisions; tenir responsabilitat en la participació, sense fractures de primacia o de deixadesa; exercir la democràcia sense complexos, com a finalitat d'organització; la valoració positiva que l'acte d'aprenentatge i de saber aporten noves perspectives per enriquir el debat; i potenciar la constància i la persistència per l'obtenció de resultats. Aquests elements, pobres en format individual, traslladats a l'àmbit educatiu en perspectiva de grup agafen un sentit de cooperació, oferint tot un potencial social i democràtic que permet formar alumnes compromesos amb esperit de superació futura.

Per l'indicat fins aquí, l'estructuració cooperativa de l'aprenentatge a l'aula és molt més que treballar en grup esporàdicament. Ara bé, no és el mateix treballar en grup o en equip que treballar en grups cooperatius. Encara avui, existeix una clara associació perversa d'aquestes dues dinàmiques de treball. En el treball en grup es presta més atenció a la composició del grup que no pas a la implementació del resultat final d’aquest sistema d’organització. S'utilitza, a més, per resoldre tasques basades en plantejaments densenyament-aprenentatge individual, fet que constitueix el grup com a addició de cada una de les parts (Traver, 2009: 20 i 21), descuidant la visió educativa col-laborativa que ha de tenir el grup.

Així, el treball en grups cooperatius parteix d'altres principis. D’entrada empeny els seus membres a interaccionar necessàriament amb els altres, fent que la passivitat quedi relegada. Implica afrontar reptes comuns, acceptar compromisos, reconèixer la feina ben feta, col-laborar per la consecució d'un objectiu, parlar per donar opinió, acceptar els raonaments dels altres i acceptar-los si estan fonamentats... Talment, permet desenvolupar el sentit de la responsabilitat individual: desplegar les pròpies potencialitats $i$ valorar les de la resta amb l'objectiu únic d'aconseguir resoldre la tasca encomanada de forma conjunta. Un sistema d'organització de tasques allunyat d'actituds competitives, on tothom es beneficia de la pràctica col-lectiva fonamentada amb l'ajuda mútua. Una eina de treball que afa- 
voreix la comunicació necessària entre els seus membres (Connac, 2010: 39-40).

Difícilment els futurs mestres podran ensenyar a treballar cooperativament si abans no hi han treballat a l'escola, a l'institut i a la universitat. Creiem que deixar aquesta forma d'aprenentatge a necessitats particulars del moment, dels alumnes o estudiants no facilita una comprensió adequada, i llavors surten els treballs per grups, basats en la intuïció com a base. És per això, per desterrar aquesta pràctica nociva, que les àrees implicades en aquest article hem apostat per la incorporació del treball cooperatiu en els diversos programes universitaris, no pas de forma aleatòria, sinó fruit de l'èxit corroborat per autors destacats com ara Coll (1984), Kagan (1999) i Johnson \& Johnson (2004), els quals han implementat estratègies cooperatives entre l'alumnat d'educació primària i de secundària. Des d'aquestes mateixes àrees que signem el treball considerem que el treball cooperatiu és una bona eina per gestionar l'aula amb garantia d'èxit, permetre la inclusió activa i participativa de l'alumnat en el procés de construcció de l'aprenentatge, afavorir la relació i la interacció entre els alumnes i millorar el rendiment acadèmic. Per tal de palesar la funcionalitat del treball cooperatiu, hem experimentat diverses pràctiques de forma cooperativa amb els nostres alumnes, hem estudiat les dinàmiques cooperatives que s'esdevenen entre els diversos grups de treball i hem atès la valoració de l'alumnat implicat sobre la formació referida al treball cooperatiu impartit durant el període de formació universitària.

\section{Jo puc, tu pots, ell pot, nosaltres podem...}

A continuació exposem les diferents propostes que s'han generat. Que parlin!

\section{a. Treball cooperatiu a la Universitat de Vic}

Experiència 1. Lactivitat d'aprenentatge cooperatiu es va desenvolupar en el marc de l'assignatura Didàctica de les Ciències Socials II, obligatòria a quart curs del grau d'Educació Primària, durant el curs 2014-2015. L'experiència implicà un total de 86 alumnes autoorganitzats en grups d'entre 3 i 4 membres. S’encomanà l'organització d'una sortida de treball per la ciutat de Vic, inspirada en una visita prèvia, inicial, realitzada per fixar i per donar valor al patrimoni local en el marc de la mateixa assignatura. Abans, però, d'endinsar-se en la tasca es treballà la lectura d'un treball específic en el qual sespecificaven les contribucions del treball cooperatiu a l'ensenyament primari. Posteriorment l'alumnat havia de concretar una sortida de treball, especificant el curs i l'objectiu que es pretenia, i seqüenciar un seguit d'activitats a realitzar. El programa de treball incorporà nombroses tutories grupals personalitzades mitjançant les quals es feia seguiment de la dinàmica de treball i del producte elaborat. Lactivitat finalitzà amb dues simulacions reals escollides a l'atzar, in situ, al lloc de treball.

Experiència 2. Lactivitat d'aprenentatge cooperatiu, en aquest cas, es desenvolupà en el marc de l'assignatura Festes i Cultura Popular a l'Escola, optativa de quart curs dels graus d'Educació Infantil i Primària durant el curs 2014-2015. Implicà un total de 36 alumnes organitzats en dos grups de treball (matí i tarda). Prèviament a l'activitat es dedicà una sessió a exposar metodologies cooperatives diverses i s'organitzà una dinàmica d'aula per tal d'exemplificar-les. L'alumnat havia de dissenyar la celebració de la festa de Sant Nicolau, adoptant el format d'una comissió de festes. Més concretament, havia d'enllestir un carta dirigida al deganat amb els seus propòsits, un butlletí informatiu que inclogués l'explicació de la tradició i el programa d’actes, un cartell anunciant la festa i tot el material necessari per fer-la possible (disfresses, menjars i beures, pancartes, arbre dels desitjos, etc.). Lactivitat finalitzà amb la celebració real de les dues propostes concretades.

b. Treball cooperatiu a la Universitat Rovira i Virgili-Àrea de didàctica de les Matemàtiques:

Experiència 1. Lactivitat d'aprenentatge cooperatiu es desenvolupà en el marc de l'assignatura Ensenyament i Aprenentatge de les Matemàtiques I, obligatòria de segon curs del grau d'Educació Primària durant el curs 2014-15. Lexperiència implicà un total d'entre 60 i 70 alumnes organitzats grupalment de forma heterogènia. Es consignà als membres dels grups de confrontar $\mathrm{i}$ 
verbalitzar la diverses perspectives front el problema i les possibilitats de solució. La intenció va anar més enllà de promoure un pensament reflexiu sobre què vol dir i aprendre matemàtiques a l'escola. Per estimular la dinàmica cooperativa es donà una recompensa en la valoració final: si la totalitat dels membres aconseguia una nota no inferior al notable, rebrien un arrodoniment a l'alça o de mig punt a la qualificació final. La tasca encomanda proposava resoldre qüestions $\mathrm{i}$ problemes del camp de les matemàtiques escolars, en el sentit de confrontar i verbalitzar cada grup com veia inicialment el problema i la possible solució en aspectes referits a nombres i càlcul elemental, nocions bàsiques de probabilitat i mesura i, càlculs geomètrics senzills. Lactivitat finalitzà amb la consecució d'un seguit de presentacions orals i pràctiques per part de diversos grups de treball.

Experiència 2. L'activitat d'aprenentatge cooperatiu es desenvolupà en el marc de l'assignatura Ensenyament i Aprenentatge de les Matemàtiques II, obligatòria de tercer curs del grau d'Educació Primària durant el curs 2014-15. L'experiència implicà, de nou, un total d'entre 60 i 70 alumnes, en aquest cas, auto-organitzats en grups de 3 o 4 integrants. Cada grup havia de resoldre un problema de tipus didàctic, diferent. Un exemple: dissenyar i concretar curricularment una activitat per tal de conscienciar els alumnes de tercer de primària de la grandària del número 1.000. El grup proposà l'activitat i com dur-la a terme. La professora de la Facultat assenyala per sorteig qui hagué d'actuar del grup, a fi i efecte que tots tinguessin arguments sòlids d'exposició davant la resta de companys. Lactivitat finalitzà amb la consecució d'un seguit de presentacions orals, pràctiques, per part de diversos grups de treball.

\section{c. Treball cooperatiu a la Universitat Rovira $i$ Vir- gili (Àrea de Didàctica de les Ciències Socials)}

Observació de dinàmiques de funcionament grupal en termes cooperatius. L'estudi s'efectuà en el marc de l'assignatura Ensenyament i Aprenentatge de les Ciències Socials II, obligatòria de quart curs del grau d'Educació Primària, durant el curs 2014-2015. La investigació implicà un to- tal de 26 grups conformats per 3 o 4 membres. Prèviament, el grup classe ja havia rebut formació cooperativa mitjançant la lectura de diverses publicacions actuals i l'elaboració d'un treball específic sobre valors cooperatius. L'alumnat, per grups, havia de plantejar la comprensió d'un dels tres grans blocs del disseny curricular de primària, amb els termes següents: refer amb paraules planeres els diversos objectius curriculars del bloc, plantejar un títol que facilités l'aprenentatge parcial de l'objectiu i enllestir una seqüència d'activitats d'acord amb els apartats anteriors. La tasca es realitzà a classe, en la qual el professor assessorà didàcticament els diversos grups, $\mathrm{i}$ també fora de l'horari lectiu. L'observació de les dinàmiques cooperatives s'efectuà a la classe mitjançant observadors externs, mestres vinculats al grup de recerca. Aquests omplien una pauta sobre els aspectes observats: lideratge o no, la solució al tractament d'idees divergents, l'eficiència en l’organització i la cohesió grupal...

Un cop acabat, es passà una enquesta de valoració de treball cooperatiu en la formació de mestres. A partir d'un qüestionari individualitzat respongueren 88 estudiants. L'enquesta recollí la informació següent: 1) les assignatures de grau en les quals s'havia parlat de cooperació i el tipus de formació rebuda (teòrica, pràctica o teoricopràctica); 2) l'ordenació de l'apartat anterior tot indicant el percentatge que ocupava la matèria cooperativa del conjunt de l'assignatura, i 3) si la formació obtinguda es considerava apta per aplicar dinàmiques cooperatives en la seva dedicació professional imminent.

\section{Resultats per a tots els gustos. Pensar per mi- llorar}

De l'observació de les experiències didàctiques amb treball cooperatiu s'han tret una sèrie de conclusions, que adjuntem, assenyalant la universitat que ho ha detectat amb més concreció. Remarquem les més significatives.

a) Lalumnat dels grups ha mostrat dificultats per assumir les tasques de treball cooperatiu de forma autònoma. S'ha visualitzat que als alumnes se'ls forma amb temor a l'errada, i per això reclamen amb assiduitat el guiatge i coordinació 


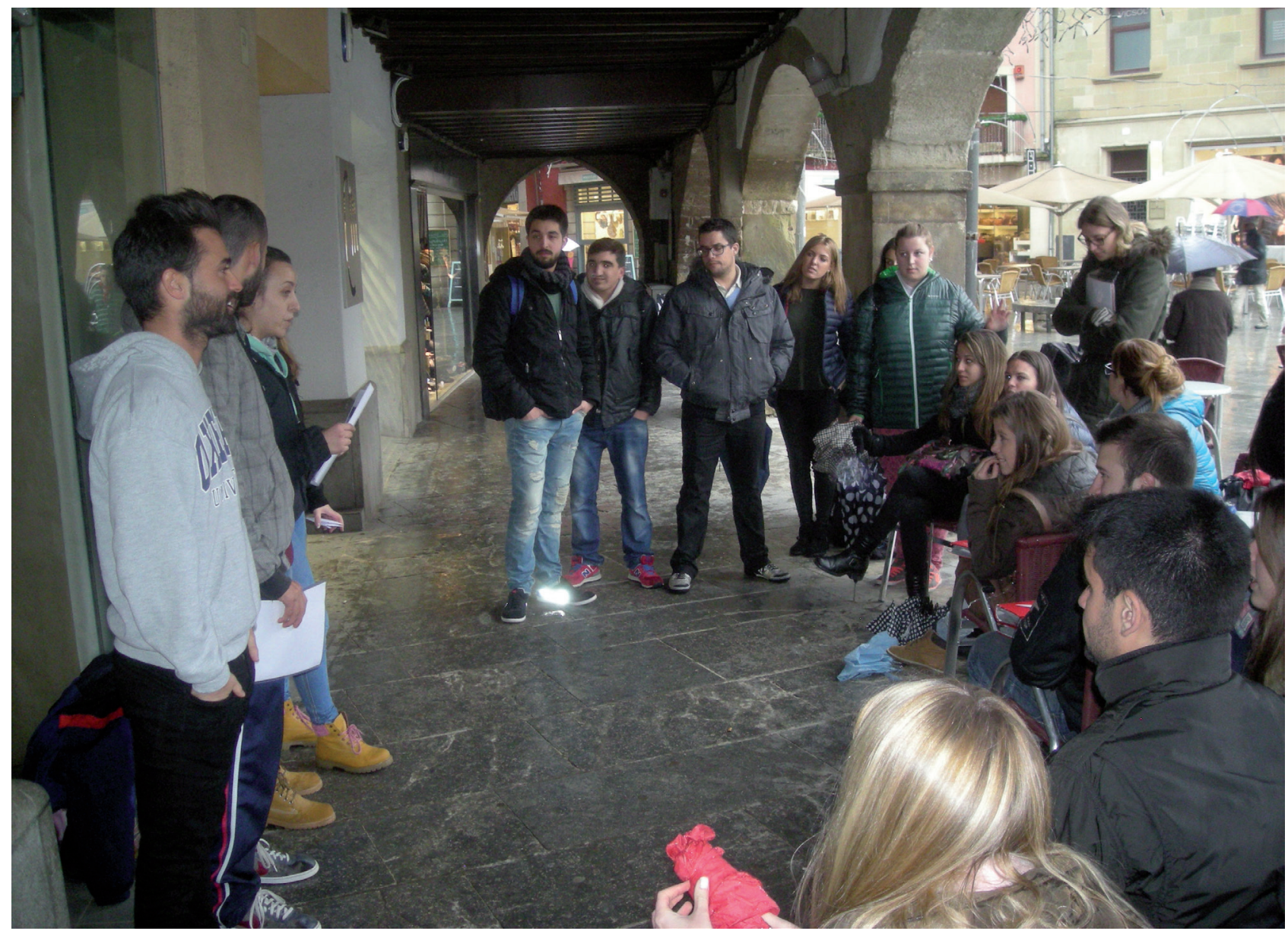

del professorat. Sobserven dificultats a l'hora d'organitzar-se, establir objectius, planificar tasques i revisar el seu propi funcionament (UVic, URV).

b) S'aprecia en l'alumnat manca de consciència de pertinença a un projecte comú, en aquest cas cooperatiu, quan es treballa en paral.lel amb altres grups que no coincideixen temporalment, però que han de resoldre les mateixes qüestions. S'ha detectat que costa empatitzar entre dos grups d'alumnes, de matí i tarda, fruit segurament de l'excés d'individualisme promulgat al llarg de la carrera universitària i també que un grup es veu diferent d'un altre, malgrat ser de la mateixa universitat (UVic).

c) La temporització regulada de les experiències no permet abordar les tasques amb la tranquil.litat necessària. Es detecta que a les primeres sessions es practica l'ajuda mútua entre els seus membres. Ara bé, la relaxació i l'afany per resoldre les activitats en els terminis establerts comporta, en les darreres sessions, quan han d'acabar el treball, el repartiment de tasques parcials i individuals entre els membres del grup. Aquesta incidència de planificació temporal s'aprecia en el resultat final de l'experiència: la qualitat dels treballs d'estructura cooperativa no posa de relleu les habilitats que els alumnes havien evidenciat en les primeres sessions. Es constata, per tant, que el treball cooperatiu necessita més temps i una temporització més laxa (UVic, URV).

d) En l'anàlisi de les dinàmiques de treball grupal en termes cooperatius es posà de manifest l'existència de lideratges, els quals, en alguns casos, incideixen positivament o no. Sota aquesta premissa sobserva que, en alguns grups, els seus membres accepten majoritàriament una idea concreta dictada pel líder sense contrastar-la prèviament. Això implica que en alguns casos no existeixi discussió reflexiva d'idees divergents (UVic, URV).

e) S'ha observat que hi ha alumnes, futurs mestres, que contribueixen poc al treball coope- 
ratiu, quant a idees i treball. S'ha detectat que, acostumats al sistema de demanar treballs en grup, alguns no aporten un plus de treball cooperatiu i el converteixen en un mer treball de conjunt, no assumit. Això evidencia que incorporen tics del treball en grup i no contribueixen en el nou treball de forma cooperativa. Considerem que el treball cooperatiu, almenys en els seus inicis, ha de ser seguit, valorat i avaluat pel professor per poder-ne captar la riquesa individual tramesa al grup, i per ajudar a implicar i retocar comportaments per a un veritable treball cooperatiu (UVic, URV).

f) En la valoració del treball cooperatiu en els alumnes del grau d'Educació Primària que acaben el cicle, sorgida de l'aplicació de les enquestes, s'evidencià que el treball cooperatiu és present, de mitjana, en un total de només quatre assignatures del grau. Cal significar, per tant, que és una xifra exigua que demostra que la pràctica no és generalitzada. Talment, complert el cicle i propers a graduar-se, un 52,3\% de l'alumnat enquestat l'inclouria en la seva pràctica docent, aspecte que demostra que la inèrcia del treball individual prima encara molt per sobre el treball cooperatiu i que s'està lluny de validar una pràctica que costa d'adoptar (URV).

g) Un gruix important d'alumnes (un 52\%) que han passat per un treball cooperatiu seriós, quant a temps i nota, en una primera fase no han arribat al mínim exigit. Un cop corregit, avaluat i justificat grup a grup per part del professor, la majoria dels grups (un 85\%) han demanat una segona opció per refer l'estudi. La segona opció ha resultat sensiblement millorada. S'ha constatat que en la primera presentació treballada tant a classe com externament el treball cooperatiu no seguia els mateixos paràmetres. Mentre internament a classe se seguia la norma, a fora es desvirtuava i hi prevalia el treball individual. Això demostraria que els primers treballs cooperatius han de realitzar-se sencers a classe (URV).

h) El professorat implicat en el seguit d'experiències i treballs d'investigació insistim en una premissa: cal fomentar l'ús de dinàmiques cooperatives, ja que aquestes permeten construir el coneixement a partir de les relacions socials entre l'alumnat. Cal incloure aquest tipus d'estratègies en els tempos de les assignatures; una aposta ferma cap a l'escola inclusiva i de qualitat (UVic, URV).

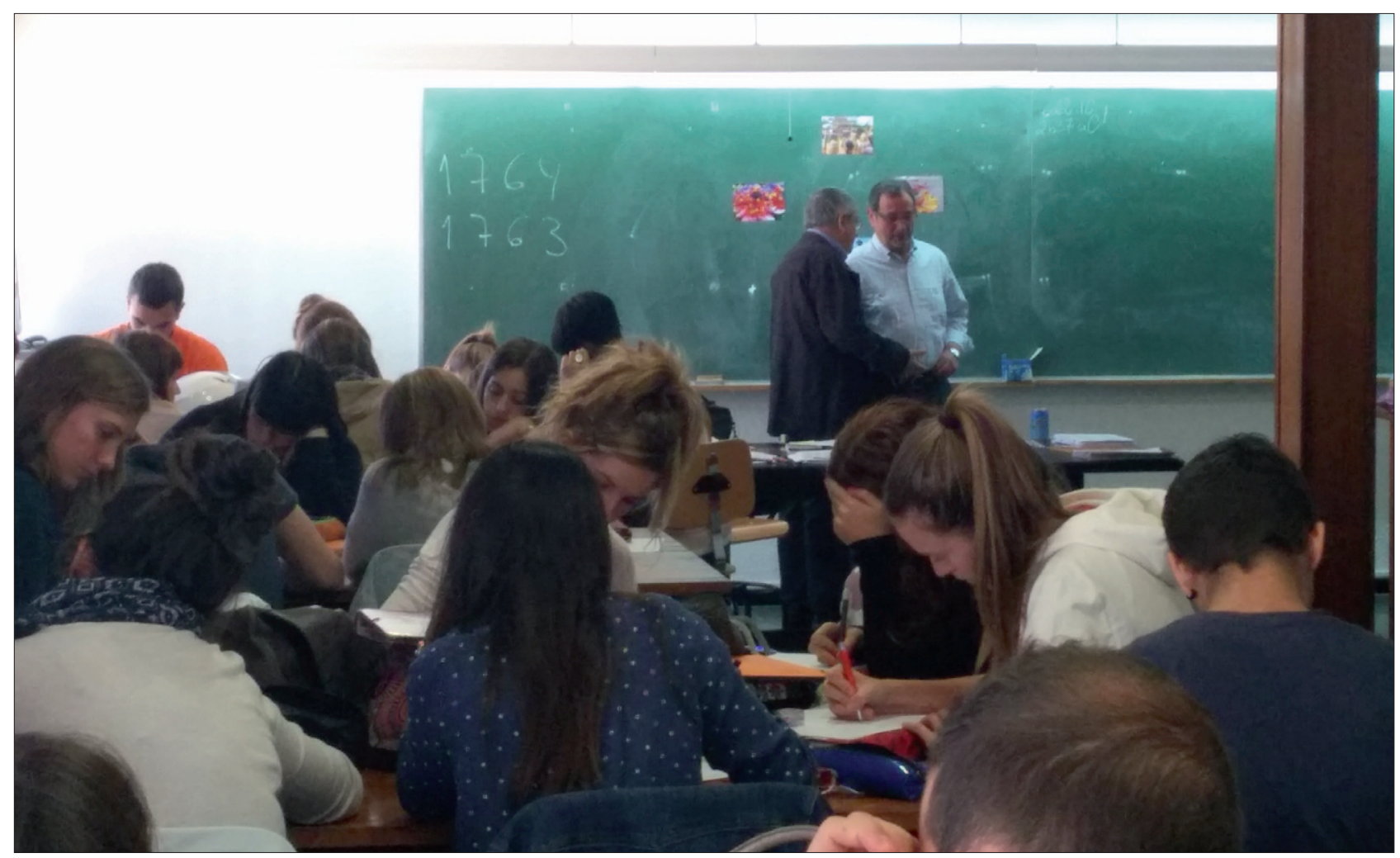




\section{Només sortint el sol no es generalitza una forma de treball!}

Pel que s'ha exposat en les pàgines precedents i per altres estudis disponibles es detecta, d'entrada, que el treball cooperatiu, eina bàsica per arbitrar un ensenyament més igualitari i social, està encara a les beceroles, amb les excepcions de rigor. Això valida que la teoria no és el mitjà definitori per fer canvis a l'ensenyament, aspecte que ja se sap per altres fòrums, i que sense una pràctica adequada i persistent l'alumne futur mestre no detecta la potencialitat del canvi.

La pregunta del perquè no ha arrelat o costa d'arrelar, basada en les evidències de les diferents maneres de treball aplicades i explicades succintament, creiem que passa per diversos factors, concatenats, que aquí només apuntem sense ànim d'exhaustivitat:

a) Un és l'escassa massa crítica des de la mateixa estructura de la universitat de com formar professionals de l'ensenyament. La preponderància manifesta, creixent, de donar pautes de com s'ha de resoldre l'ensenyament-aprenentatge des de qualsevol ciència sense després fer-la servir, s'ha demostrat que no condueix a res o a ben poc. Lexcessiva teoria llibresca que no porta a la pràctica, i més en uns estudis professionalitzadors, indueix a tenir nocions generals no arrelades, falta de pràctica real. Cal convenir que en aquest projecte les pràctiques s'han realitzat sobre continguts concrets.

b) Un altre factor del perquè els resultats no han estat del tot satisfactoris té a veure amb la temporalitat, en el sentit que treballar de forma cooperativa implica dedicar més temps al que sestà treballant. Òbviament això implica també que s'ha d'ensenyar l'alumne a dominar el temps des de la universitat, i no que el temps el domini a ell. El compromís de fer més autònoms els futurs professionals que s'han de dedicar a l'ensenyament passa per saber gestionar el temps, que en aquest cas és compartit.

c) Altrament, en positiu, els alumnes s'han adonat que els treballs finals realitzats en format cooperatiu tenen un plus més de qualitat que de quantitat. Això ens porta a manifestar que el treball cooperatiu pot aportar elements de debat a la comprensió de la ciència, segurament més reposada però més efectiva, més significativa. I més interrelacionada.

d) Un altre factor que hem detectat són respecte als programes. Aquests, sovint rígids, assenyalen les orientacions dels continguts que s'han d'ensenyar, que per als qui s'ho creuen desborden la capacitat d'innovar, o si més no de treballar de manera diferent. Això implica que formar el professional hauria de tenir molt de criteri i pes educatiu: saber decidir què interessa per a uns alumnes en concret i què no interessa tant per a aquell mateix grup d'alumnes. Si posar controls de comprensió de continguts procedimentals per a la política educativa és útil i necessari, per reformular aprenentatges esbiaixats els filtres de revàlides que sanuncien no ajudaran a la consecució de treballs diferenciats.

e) Cal donar molt de valor al seguiment del treball. Aquest no ha de ser rutinari, de compromís, que sacaba quan es lliura el treball definitiu i es posa una nota. Precisament en la redacció inicial comença la part important del procés. El treball cooperatiu necessita revisar i potser reformular aspectes a partir de criteris objectivables. Educar en valors cooperatius implica que els alumnes fixen objectius realistes, que en el repartiment de tasques cada un aporti una part, en major o menor mesura de compromís segons les capacitats individuals, i que un cop realitzada ha de saber explicar a la resta per tal que la resta l'entenguin i s'ho facin seu, sense preeminències. Aquest procés de presentació i d’adquisició conceptual del treball dels altres permetrà avançar per fixar noves metes, assumibles. Retocar sempre el que faci falta, en connexió amb les idees consensuades de tothom. Cal mirar d'evitar el dirigisme del treball, i propiciar els encerts i els errors, veritable escola d'aprenentatge.

f) Cal donar valor a l'avaluació. Creiem que hi ha d'haver una nota de grup i una d'individual. La nota de grup significa valorar el resultat conforme es va desenvolupant el procés i si el treball ha permès avançar a tot el grup, en el grau de maduració que cadascú ha aportat de bon començament, ja que cada alumne és diferent de l'altre del grup. Un grup veritablement és cooperatiu quan tots els components del grup han avançat, la qual cosa significa que ho han fet en major o menor 
mesura en format individual i de grup. Si quan s'ha lliurat un treball el grup està capacitat per decidir com seguir a continuació, presentant noves formes d'avançar i com activar-ho, el grup ha progressat ostensiblement.

Resumint: Una escola inclusiva és aquella que prepara per a la vida. Si volem alumnes autònoms, amb capacitat de pensar, reflexius i amb capacitat de decisió, i no màquines de repetició, el treball cooperatiu ha d'entrar inexorablement a les aules. Fomentar la individualitat comporta fer un model de societat dominada per uns pocs elements, propensa a dogmatismes. Fomentar el treball cooperatiu implica educar individus amb raonament, amb convenciment de participació, amb capacitat de crítica i de consens, amb possibilitat de connexió amb d’altres. La societat plural demana i necessita precisament això.

És per això que apostem per una forma de treballar diferent en els futurs professionals, basada tant en l'esforç personal com en la conjunció al treball en equip. Educar en valors cooperatius implica traslladar-los a la classe i veure'n els avantatges: saber i voler treballar en grup, agafar responsabilitat en la participació, desterrar la passivitat, engrescar en la formulació d'hipòtesis, ser solidari amb el que se sap, mostrar inquietud pel que no es domina, activar la curiositat pel saber i per la investigació, qüestionar el contingut que es vol transmetre, acceptar l'orientació i la crítica interna, remuntar el vol davant d'una acció desencertada, saber argumentar en defensa d'una proposta pròpia, acceptar les idees divergents davant de la pròpia, no decebre el grup a l'hora de posar-hi tot l'interès necessari per un objectiu comú...
Creiem fermament que, si es parteix d'aquestes premisses i es vol que l'alumne surti amarat d'activar avenços en el seu aprenentatge des d'una base cooperativa, cal actuar en diversos fronts, interrelacionats, amb la idea de base que educació no és transmissió sinó participació. Caldrà seguir.

\section{Bibliografia:}

Coll, C. (1984). "Estructura grupal, interacción entre alumnos y aprendizaje escolar. Infancia y Aprendizaje". Journal for the Study of Education and Development, 27/28, 119-138.

Connac, S. (2011). "Impacte de la cooperació en l'aprenentatge escolar". Dins Diversos AUTORs. Treball cooperatiu: Utopia o realitat? 45a Escola d'Estiu de l'Associació de Mestres Rosa Sensat (pp. 33-47). Barcelona: Associació de Mestres Rosa Sensat.

GavaldÀ, A. (2000). "Com abordar els valors cooperatius a l'ensenyament?" Cooperació $\mathrm{Ca}$ talana, 226, 14- 17.

Johnson, D. i Johnson, R. (2004). Assessing students in groups. Prometing groups responsabiliti ans individual accountability. California: Corwin Press.

Kagan, S. (1999). Cooperative Learning. Sant Clemente: Resources for Teachers.

Pujolàs, P. (2008). "Cooperar per aprendre i aprendre a cooperar: el treball en equips cooperatius com a recurs i com a contingut". Suports: revista catalana d'educació especial i atenció a la diversitat, 12 (1), 21-37.

Traver, J. A. (2009). "Aprendre cooperant per aprendre a cooperar". Comunicació Educativa. Revista d'Ensenyament de les Comarques Meridionals de Catalunya, 22, 20-25. 